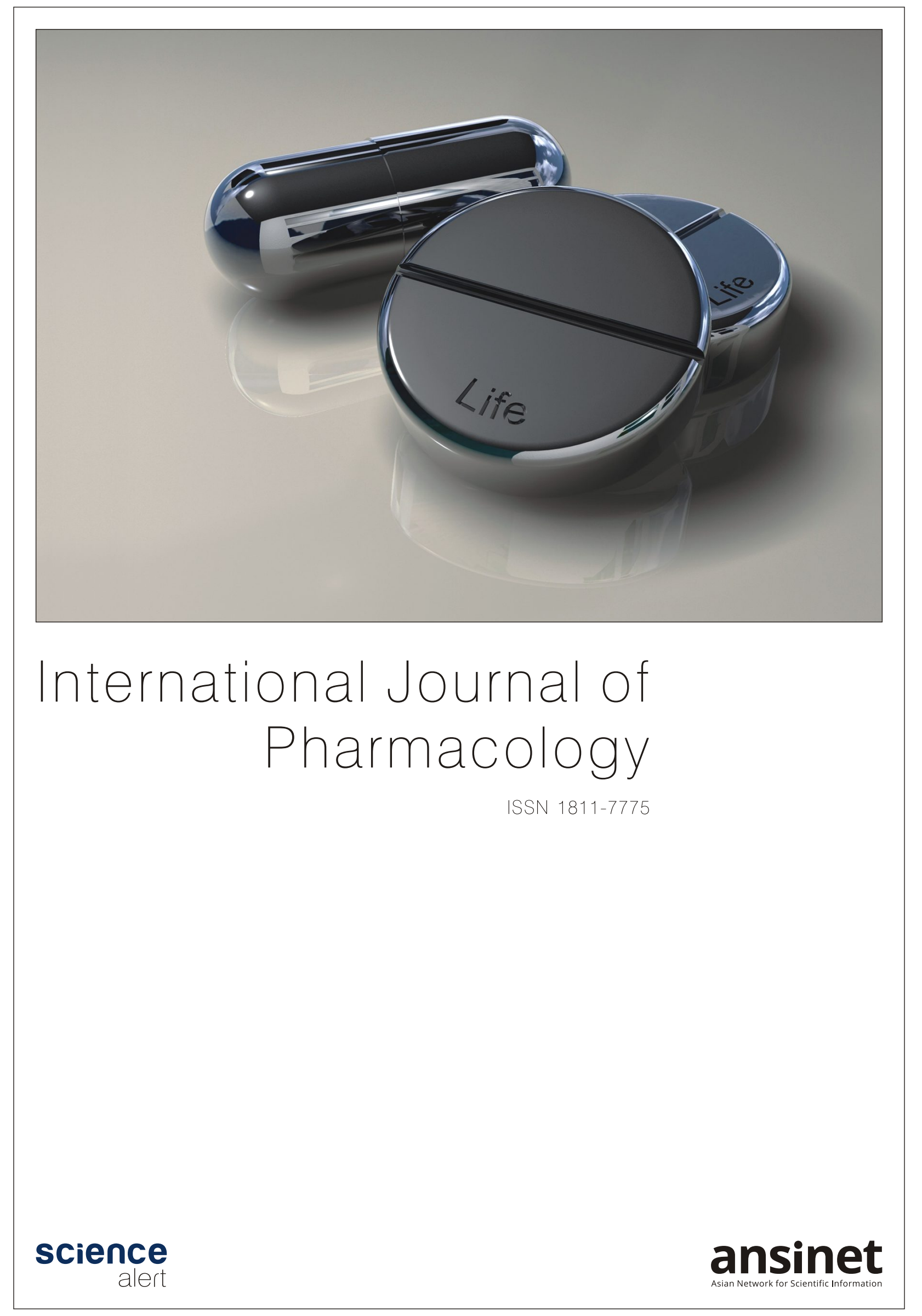




\title{
Research Article Anti-diabetic Potential of Cordia dichotoma Pulp and Peel (Functional Fiber) in Type II Diabetic Rats
}

\author{
${ }^{1}$ Sherif Salah Mohamed and ${ }^{2}$ Abeer El Sayed Elkhamisy \\ ${ }^{1}$ Department of Nutrition and Food Science, National Research Centre, Dokki, Giza, Egypt \\ ${ }^{2}$ Department of Nutrition and Food Sciences, Faculty of Specific Education, Port Said University, Egypt
}

\section{Abstract}

Background and Objective: A lot of plants have been used traditionally in the treatment diabetic patient for a long time ago. Cordia dichotoma fruits constituents i.e., pulp or seeds comprises of important compounds which have great health benefits. The current study was conducted to investigate the anti-diabetic potential effect of fruits pulp and peel of Cordia dichotoma (C. dichotoma) powder against diabetes mellitus type 2. Materials and Methods: About 24 adult male rats were randomly distributed into to 3 groups each group comprises to 8 rats. The 1 st group (I) was fed on the standard normal diet. The 2 nd group (II) was given high fat diet (HFD) to induction rats to be obese and after that to be diabetic by long run period and 3rd group (III) was demonstrated HFD+10\% of $C$. dichotoma pulp+peel fiber powder. At the end of the trial, rats were weighted and blood samples were collected for estimating serum biomarkers of diabetes as well as blood glucose, insulin, Leptin and oxidative stress. Results: The results showed that supplemented diet with C. dichotoma powder in 3rd group (III) caused significant increase slightly in body weight gain. Also, The C. dichotoma powder significant decreases in serum levels of blood glucose, AST, ALT, total bilirubin and alkaline phosphatase enzyme in rats. It also had significant increase in serum creatinine. The $C$. dichotoma powder decreased serum levels of (LDL), triglycerides (TG), total cholesterol (TC) levels, malondialdehyde (MDA) and increased in HDL levels and activity of antioxidant enzymes. Conclusion: Therefore, intake of C. dichotoma pulp+peel fiber powder should be beneficial for the prevention and controlling of diabetic hazards.

Key words: Cordia dichotoma, high fat diet, diabetes type-2, oxidative stress, leptin, malondialdehyde

Received: August 31, $2018 \quad$ Accepted: October 13, $2018 \quad$ Published: December 15, 2018

Citation: Sherif Salah Mohamed and Abeer El Sayed Elkhamisy, 2019. Anti-diabetic potential of Cordia dichotoma pulp and peel (functional fiber) in type II diabetic rats. Int. J. Pharmacol., 15: 102-109.

Corresponding Author: Sherif Salah Mohamed, Department of Nutrition and Food Science, National Research Centre, Dokki, Giza, Egypt Tel: +201002276780

Copyright: (9) 2019 Sherif Salah Mohamed and Abeer El Sayed Elkhamisy. This is an open access article distributed under the terms of the creative commons attribution License, which permits unrestricted use, distribution and reproduction in any medium, provided the original author and source are credited.

Competing Interest: The authors have declared that no competing interest exists.

Data Availability: All relevant data are within the paper and its supporting information files. 


\section{INTRODUCTION}

Every year 2.8 million of overweight and obesity were died, this number from data noted in the report of WHO'. Many disease incidence as well as heart disease, cancer and diabetes increase constantly with mounting body weight. The prevalence of obesity occurring diabetes mellitus is highest in high income and middle income countries, also reported that obesity become in upper levels from some lower-middle income countries. Disorder of metabolic syndrome disease of dyslipidemia, hyperinsulinemia, hypertension and hyperuricemia is a condition describe by variable co-existence of obesity disease side effects certainly lead to many disease as the cardio-renal system ${ }^{2}$.

In Egypt about $15.5 \%$ of the adult population was obese (Nearly: 12.573 .767 adults) ${ }^{3}$. This disease is mainly due to changes in eating habits: low-fiber and high-fat diets. The high score of serum total cholesterol and low-density lipoprotein (LDLC) as well as serious dramatic changes of other lipid parameters has been implicated as a primary hazard for cardiovascular disease ${ }^{4}$. Therefore, reduce serum cholesterol and other parameters, particularly LDLc levels in diabetic suffer from hypercholesterolemia, is desirable treat in this same condition. The same notion in reducing LDL-c depend on inhibiting cholesterol synthesis ${ }^{5}$ blocking the absorption of dietary cholesterol ${ }^{6}$. The number of people mal of diabetic disease worldwide become rapid increase at an alarming rate account in 2000 estimated 191 million with expected as against nearly 366 million peoples potential to be diabetic by the year ${ }^{7} 2030$. So, actually the need of those people suffering from diabetic syndrome and complications with deprive of sweets and many fruits, it may due to afraid of elevation blood glucose level. Otherwise, increase in diabetic numbers alongside adiabatic complication in type 2 , a few studies was concerned in this scope to produce many fruits or its products to diabetic people. Really, it's very important to precede many studies in this specific field.

Cordia dichotoma (Boraginaceae) is tree of tropical and subtropical regions, commonly known as Lasaura/Lasura and in Egypt the tree called Mokheit. The fruits are globs, yellowish, brown, pink or black and pulpy ${ }^{8}$. All organs of Cordia dichotoma (C. dichotoma); fruits constituents which pulp or seeds are comprised important compound had a healthy benefits and many healthy biological action nutrient. Fruit is high nutritious: rich source of fibers, carbohydrates, protein, vitamins and minerals. Also, fruit contained high antioxidant compounds i.e. (polyphenols content, flavonoids, tannins and saponins) $)^{9}$. The fruit pulp of the $C$. dichotoma was focused on antidiabetic activity on the healthy Wistar albino male rats. Alloxan induced diabetic rat studies were randomly operated into four groups each having 6 rats. Significant decrease in blood glucose value and the rat body weight loss was observed in glucose high level in alloxan induced diabetic rats when treated with methanol extract of fruits pulp, which reveals antidiabetic potential of fruits pulp of $C$. dichotoma and this can be useful for the control of diabetes mellitus ${ }^{10}$.

Cordia dichotoma is fruit used to remedy treatment to relive several diseases as anti-diabetic, immunomodulator, hepatoprotective, treatment of inflammation, fever, bronchitis and astringent, wounds healing and paralytic in folk medicine. Moreover, it authenticated as promote wound healing, to relief severe colic pain, to improve memory, to treat anxiety, antimicrobial, hypoglycemic and treat eczema ${ }^{10}$. So, this research study antidiabetic and hypoglycemic efficacy of C. dichotoma shell and pulp fruit to reduce hazard of obesity which induction rats to type 2 diabetes mellitus. Otherwise, the worth of oxidative stress result to induced diabetic rat with high postprandial blood glucose in order to the outer shell and pulp fruit fiber and active ingredient effect on Leptin hormone and as antioxidant agents ${ }^{11}$. This current study aimed to investigate the anti-diabetic potential effect of C. dichotoma pulp and peel which into can be useful for the control of diabetes mellitus.

\section{MATERIALS AND METHODS}

\section{Materials}

Cordia dichotoma: The C. dichotoma collected of wield C. dichotoma trees growth widespread around the banks of River Nile in Egypt during August, 2017.

Rats and normal basal diet: Dawley male rats were obtained from the animal house of the National Research Centre, their body weight $135 \pm 25 \mathrm{~g}$. The diet formula preparations of ingredients given to the animals were purchased from the local market. Casein was obtained from Sisco Research Laboratories PVT. LTD, India. Salts and vitamins used for the preparation of the salt and vitamin mixtures were obtained from Merck, Germany and prepared according to AIN $93^{12}$.

Chemicals: Kits used for the estimation of the analyzed parameters were obtained from Biodiagnostic company, Egypt. 


\section{Methods}

Cordia dichotomy pulp and peel dietary fiber powder preparation: The outer fiber peel (external fiber cover) of the fruits and viscid sweetish transparent pulp surrounding a central stony part (internal seeds) were separated but stony part discarded (The two parts yields of edible fruits from which a very sticky white substance could be extracted for gluing purposes content was separated of $C$. dichotoma fruits and outer peel without the seed) dried the indirect solar dryers, the black surface heats incoming air, rather than directly heating the substance to be dried in National Research Centre for two days. The dried pulp and fiber of peel were grinded with the Moulinex Blender the genuine $400 \mathrm{~W}$ made in France. Grinded pulp to powder was kept in packet at $5 \pm 1{ }^{\circ} \mathrm{C}$ until using.

Chemical composition: Moisture, protein, Fat, ash and crude fiber contents were determined according to $A O A C^{13}$. Carbohydrates were calculated by difference as mentioned as follows:

$$
\text { Carbohydrates }=100 \text {-protein }+ \text { fat }+ \text { ash }+ \text { crude fiber }(\%)
$$

Fiber fractions: The content of fibers, hemicellulose, cellulose, neutral detergent fiber (NDF), acid detergent fiber (ADF), acid detergent lignin (ADL) and lignin were determined by using Fiber tec system velp014_en fiber extractor 3-6 posts fisher bioblock scientific ${ }^{14}$.

Sequential analysis: The different constituents of the plants can be determined sequentially according to the following in Fig. 1:

Experimental rats design: The animal experiment is Dawley male rats were divided to 3 groups each group comprise to 8 rats. The 1st group (I) was fed on the standard normal diet according $^{12}$ to AIN-93. The 2 nd group (II) was given high fat diet (HFD) to induction rats to be obese and after that to be diabetic by long run period (three months) and 3rd group (III) was demonstrated HFD+10\% of C. dichotoma pulp+peel fiber powder.

Animals were housed individually in stainless steel cages, the different diet and distilled water was allowed to every group a libitum and the room temperature was adjusted at $25^{\circ} \mathrm{C}$. The feeding period continued for 6 weeks for induction obesity (start first of June) and after duration nearly three months (end 15 September 2017) to induction diabetic rats. During the experimental period the body weight of the animals were followed. The experimental procedure was carried out according to the Institutional Animal Ethics Community of the NRC, Egypt. At the end of the experimental period, animals were fasted overnight and in the morning blood samples were taken from each rat by open heart puncture under slight ether anesthesia. Blood samples were left to clot at room temperature then centrifuged at $3500 \mathrm{rpm}$ and serum was separated and kept at $-20^{\circ} \mathrm{C}$ till used in chemicals analysis.

Induction rats to diabetes mellitus (high fat diet): The pelleted semi-purified, nutritionally complete experimental diets [AIN-93M] were prepared that the high fat (HFD) contained $20 \mathrm{~g}$ of fat $/ 100 \mathrm{~g}$ of diet $(19 \mathrm{~g}$ of butter oil and $1 \mathrm{~g}$ of soybean oil to provide essential fatty acids). Because, the emphasis in these experiments was on dietary fat, it equalized the amount of protein and all of the essential minerals and vitamins required for rats ${ }^{12}$ for the HFD.

\section{Biochemical parameters assay}

Serum levels of TL, TG and TC assay: Total cholesterol, serum triglycerides $\mathrm{LDL}-\mathrm{C}$ and $\mathrm{HDL}-\mathrm{C}$ evaluated by the technique described according to Allain et al. ${ }^{15}$, Fossati and Prencipe ${ }^{16}$, Levy ${ }^{17}$ and Burstein ${ }^{18}$, respectively.

\begin{tabular}{|c|c|}
\hline Sample $1 \mathrm{~g}$ & The neutral detergent extracts the contents of the cell \\
\hline Neutral Detergent Residue (NDF) & Acid detergent removes hemicelluloses \\
\hline Acid detergent residue (ADF) & $72 \%$ sulfuric acid dissolves cellulose \\
\hline Lignin-cutin complex (lignin crude) & Lignin is extracted by permanganate \\
\hline $\begin{array}{l}\text { Cutin and ash } \\
\downarrow \\
\text { Ashes }\end{array}$ & Cutin is destroyed by ash reduction at $550^{\circ} \mathrm{C}$ \\
\hline
\end{tabular}

Fig. 1: Steps of fiber fraction 
Liver functions assay: Aspartate aminotransferase (AST), Alanine aminotransferase (ALT), total bilirubin, albumin and alkaline phosphatase were estimated according to Reitman and Frankel ${ }^{19}$, Draper and Hadley ${ }^{20}$ and Bartholomew and Delaney ${ }^{21}$ respectively.

Kidney functions assay: Urea and creatinine determined according to Fawcett and Soctt $^{22}$ and Bartles et a/.23 respectively.

Determination of lipid peroxidation (LPx): Malondialdehyde assessed in blood serum according to the procedure of Satoh ${ }^{24}$.

Assay of antioxidant enzymes: Superoxide dismutase (SOD) determination based on the method developed by McCord and Fridovich ${ }^{25}$, glutathione peroxidase (GPx) According to the method described by Weinhold et al. ${ }^{26}$, Catalase (CAT) according to the method described by $\mathrm{Aebi}^{27}$ and reduced glutathione (GSH) by Ellman 28 .

The levels of hormones were evaluated with detection kit according to the manufacturer's instructions using ELISA technique. Insulin and Leptin using ELISA technique purchased from Immunosec Corporation., USA.

Statistical analysis: All studied data were statistically analyzed using Co-Stat 6.303 Software Computer Program 2004 hypothesis testing methods included one way analysis of variance (ANOVA) using Duncan Test (COSTAT-C) ${ }^{29}$.

\section{RESULTS}

The chemicals composition values as elucidated in Table 1 the most ratio component is a carbs $(68.56 \mathrm{~g} / 100 \mathrm{~g})$ in fruit pulp and peel powder. In addition, the crude fiber was $6.08 \mathrm{~g}$ per $100 \mathrm{~g}$ of powder. Cordia dechotoma fiber and pulp extremely high functional fiber and mucilage as shown in Table 2 the biggest ratio is Neutral detergent fiber (NDF) of fiber fraction (ff) was $70.39 \%$ and the lowest ratio was cellulose (2.82\%).

The data in Table 3 explained the mean rats body weight in three groups which initial weight was a significant in I, II and III were 142, 139 and $143 \mathrm{~g}$ respectively, when start the induction by HFD, during the first 6 week rats swallowing HFD primarily the obesity incidence spontaneously after that, the diabetic rat status occurring by nearly 60 days. It due to increase rat's final weight in groups II and III but just the postprandial glucose elevated the rat reduced feeding gradually through the experimental trail. So, the observation of the final weight in group I was high mean score (318 g) while the decreases mean weight in group II (191 g). The results clear that feeding on the $C$. dichotoma powder increased slightly the rat's body weight to $219 \mathrm{~g}$. It may be to minify of blood glucose level should put in consideration to administration of $C$. dechotoma fiber and pulp powder as well as Mean $\pm \mathrm{SD}, 97.00 \pm 9.86 \mathrm{mg} \mathrm{dL}^{-1}$ in group three (III) meanwhile was elevated to $159.00 \pm 19.30 \mathrm{mg} \mathrm{dL}^{-1}$ in group two (II) without feeding of $C$. dichotoma powder.

Table 1: Approximate analysis component of Cordia dichotoma pulp and dietary fiber powder

\begin{tabular}{lr}
\hline Main components & $\mathrm{g} / 100 \mathrm{~g}$ \\
\hline Moisture & $8.22 \pm 0.45$ \\
Total carbohydrates & $68.56 \pm 0.59$ \\
Crude protein & $9.59 \pm 0.66$ \\
Crude fat & $0.55 \pm 0.07$ \\
Crude fiber & $6.08 \pm 0.83$ \\
Crude ash & $7.00 \pm 0.17$ \\
\hline
\end{tabular}

Each value is Means $\pm S D$ of three replicates

Table 2: Fiber fraction component of Cordia dichotoma dietary fiber powder

\begin{tabular}{lr}
\hline Crude fiber contents & Percentage \\
\hline Neutral Detergent Fiber (NDF) & 70.39 \\
Hemicellulose & 56.74 \\
Acid Detergent Fiber (ADF) & 13.32 \\
Lignin Acid Detergent (ADL) & 8.71 \\
Lignin & 5.89 \\
Cellulose & 2.82
\end{tabular}

Table 3: Relationship between rat's weight, glucose, insulin and leptin with feeding on Cordia dichotoma powder

\begin{tabular}{|c|c|c|c|c|c|}
\hline Parameters groups & Initial weight gain (g) & Final weight gain (g) & Glucose $\left(\mathrm{mg} \mathrm{dL}^{-1}\right)$ & Insulin $\left(\mu \mathrm{IU} \mathrm{mL}^{-1}\right)$ & Leptin \\
\hline I & $142 \pm 8.55^{\mathrm{a}}$ & $318 \pm 15.23^{c}$ & $74.50 \pm 9.26^{c}$ & $5.10 \pm 1.16^{c}$ & $2.24 \pm 0.26^{c}$ \\
\hline ॥ & $139 \pm 7.98^{a}$ & $191 \pm 18.47^{a}$ & $159.00 \pm 19.30^{a}$ & $13.35 \pm 2.23^{\mathrm{a}}$ & $4.11 \pm 0.39^{\mathrm{a}}$ \\
\hline III & $143 \pm 8.43^{\mathrm{a}}$ & $219 \pm 10.21^{b}$ & $97.00 \pm 9.86^{\mathrm{b}}$ & $7.11 \pm 0.87^{b}$ & $2.69 \pm 0.67^{b}$ \\
\hline
\end{tabular}


Int. J. Pharmacol., 15 (1): 102-109, 2019

Table 4: Assessment of liver and kidney function and administration of Cordia dichotoma powder

\begin{tabular}{|c|c|c|c|c|c|c|c|}
\hline $\begin{array}{l}\text { Parameters } \\
\text { groups }\end{array}$ & $\begin{array}{l}\text { Aspartate aminotransferase } \\
\qquad\left(\mu \mathrm{mL}^{-1}\right)\end{array}$ & $\begin{array}{l}\text { Alanine aminotransferase } \\
\qquad\left(\mu \mathrm{mL}^{-1}\right)\end{array}$ & $\begin{array}{l}\text { Alkaline phosphatase } \\
\qquad\left(\mu \mathrm{mL}^{-1}\right)\end{array}$ & $\begin{array}{l}\text { Total bilirubin } \\
\left(\mu \mathrm{mL}^{-1}\right)\end{array}$ & $\begin{array}{l}\text { Albumin } \\
\left(\mathrm{g} \mathrm{dL}^{-1}\right)\end{array}$ & $\begin{array}{c}\text { Urea } \\
\left(\mathrm{mg} \mathrm{dL}^{-1}\right)\end{array}$ & $\begin{array}{l}\text { Creatinine } \\
\left(\mathrm{mg} \mathrm{dL}^{-1}\right)\end{array}$ \\
\hline 1 & $20.5 \pm 7.63^{\mathrm{ab}}$ & $18.63 \pm 5.85^{\mathrm{b}}$ & $95.13 \pm 14.08^{\mathrm{b}}$ & $0.48 \pm 0.22^{\mathrm{a}}$ & $4.26 \pm 0.76^{\mathrm{a}}$ & $48.63 \pm 5.85^{\mathrm{a}}$ & $0.44 \pm 0.14^{\mathrm{b}}$ \\
\hline II & $23.63 \pm 6.14^{\mathrm{a}}$ & $24.38 \pm 5.01^{\mathrm{a}}$ & $104.00 \pm 19.89^{\mathrm{a}}$ & $0.34 \pm 0.13^{b}$ & $3.73 \pm 0.72^{b}$ & $49.88 \pm 9.29^{a}$ & $0.56 \pm 0.10^{\mathrm{a}}$ \\
\hline III & $19.88 \pm 4.06^{\mathrm{b}}$ & $19.25 \pm 3.34^{b}$ & $99.75 \pm 6.74^{\mathrm{ab}}$ & $0.40 \pm 0.16^{\mathrm{ab}}$ & $4.22 \pm 0.72^{\mathrm{a}}$ & $48.25 \pm 12.04^{\mathrm{a}}$ & $0.46 \pm 0.10^{b}$ \\
\hline
\end{tabular}

Table 5: Effect of feeding on Cordia dichotoma powder on evaluation of lipid profile

\begin{tabular}{lcccc}
\hline Parameters groups & Cholesterol $\left(\mathrm{mg} \mathrm{dL}^{-1}\right)$ & Tri-Glyceride $\left(\mathrm{mg} \mathrm{dL}^{-1}\right)$ & High-density lipoproteins $\left(\mathrm{mg} \mathrm{dL}^{-1}\right)$ & Low-density lipoproteins $\left(\mathrm{mg} \mathrm{dl}^{-1}\right)$ \\
\hline I & $54.75 \pm 10.84^{\mathrm{b}}$ & $124.75 \pm 18.57^{\mathrm{b}}$ & $41.38 \pm 10.53^{\mathrm{a}}$ & $64.88 \pm 33.35^{\mathrm{b}}$ \\
II & $178.75 \pm 55.65^{\mathrm{a}}$ & $182.38 \pm 23.95^{\mathrm{a}}$ & $29.63 \pm 8.41^{\mathrm{b}}$ & $120.75 \pm 44.60^{\mathrm{a}}$ \\
III & $141.88 \pm 20.77^{\mathrm{b}}$ & $124.75 \pm 50.84^{\mathrm{b}}$ & $40.88 \pm 9.65^{\mathrm{a}}$ & $78.13 \pm 19.84^{\mathrm{b}}$ \\
\hline abcMeans \pm SD in each column having the same letter were not significantly different, Values with different superscript letters are significantly different at $\mathrm{p}<0.05$
\end{tabular}

Table 6: Oxidative stress status with administration of Cordia dichotoma powder in rats and antioxidant enzyme

\begin{tabular}{|c|c|c|c|c|c|}
\hline Parameters groups & $\operatorname{SOD}\left(\mu \mathrm{mg}^{-1}\right)$ & $\mathrm{Gpx}\left(\mu \mathrm{mg}^{-1}\right)$ & GSH $\left(\mathrm{mmol} \mathrm{g}^{-1}\right)$ & $\mathrm{MD}\left(\mathrm{mmol} \mathrm{mL}^{-1}\right)$ & Catalase $\left(\mathrm{U} \mathrm{mg}^{-1}\right)$ \\
\hline I & $50.88 \pm 8.45^{\mathrm{a}}$ & $180.75 \pm 11.60^{a}$ & $47.75 \pm 10.18^{\mathrm{a}}$ & $158.63 \pm 10.74^{c}$ & $62.13 \pm 14.52^{\mathrm{a}}$ \\
\hline$\|$ & $31.13 \pm 8.38^{c}$ & $130.38 \pm 13.69^{c}$ & $25.38 \pm 8.00^{c}$ & $230.38 \pm 66.45^{\mathrm{a}}$ & $37.25 \pm 10.24^{c}$ \\
\hline III & $42.38 \pm 9.50^{\mathrm{b}}$ & $155.88 \pm 22.28^{b}$ & $34.50 \pm 7.63^{b}$ & $182.00 \pm 15.12^{b}$ & $54.75 \pm 10.84^{b}$ \\
\hline
\end{tabular}

Indeed, the liver is the vital organ incorporated in lipid metabolism and prone to potential oxidative damage in hyperlipidemia occurrence. Nevertheless, in the same time kidney may be vulnerable in same time the oxidative damage with the liver but notice that a significant between liver function in Table 4. ALT and total bilirubin in normal control group I and group II feed on C. dechotoma powder. The parameters Means \pm SD level of AST, ALT and total bilirubin were $20.5 \pm 7.63,18.63 \pm 5.85$ and $0.48 \pm 0.22 \mu \mathrm{mL}^{-1}$ in normal control (I), 23.63 $\pm 6.14,24.38 \pm 5.01$ and $0.34 \pm 0.13 \mu \mathrm{mL}^{-1}$ in induction group (II) in the last group (III) $19.88 \pm 4.06$, $19.25 \pm 3.34$ and $0.40 \pm 0.16 \mu \mathrm{mL}^{-1}$ respectively in normal range. But the result observation slightly elevated in group II result to HFD feeding rats. The indication with HFD amounted to increase in group II of alkaline phosphatase value Means $\pm S D$ to $104.00 \pm 19.89$ with respect to HFD.

As expected serum lipid profile administration high-fat diet elevated cholesterol, Tri-glyceride and LDL-C significantly (178.75, 182.38 and $120.75 \mathrm{mg} \mathrm{dL}^{-1}$ ) in group II compared with rats fed on normal diet group I $(54.75,124.75$ and $64.88 \mathrm{mg} \mathrm{dL}^{-1}$ ) respectively. On the other hand, HDL-C was released to $40.88 \mathrm{mg} \mathrm{dL}^{-1}$ significantly in group treated with C. dechotoma powder Table 5.

As showed in Table 6 superoxide dismutase (SOD) reduced in positive diabetic group $\|$ the Means $\pm S D$ to $31.13 \pm 8.38 \mu \mathrm{mg}^{-1}$, catalase (CAT) to $37.25 \pm 10.24 \mathrm{U} \mathrm{mg}^{-1}$ and Glutathione peroxidase (GSH-Px) to $130.38 \pm 13.69 \mu \mathrm{mg}^{-1}$ result to raise in ROS during the digestion and metabolism HFD companied with boost of Malondialdehyde (MD) to $230.38 \pm 66.45 \mathrm{mmol} \mathrm{mL}^{-1}$. In group II C. dechotoma antioxidants can attenuate oxidative stress (oxidative damage) through the elimination of ROS and be efficacy in diminution diabetes complications as well as no significant between experimental groups but findings in SOD, GPx and catalase antioxidant enzyme in group III amounted to $42.38 \pm 9.50$, $155.88 \pm 22.28 \mu \mathrm{mg}^{-1}$ and $54.75 \pm 10.84 \mathrm{U} \mathrm{mg}^{-1}$ respectively near to the normal control (group I).

\section{DISCUSSION}

In the beginning, rats dependently feed with high fat diet (HFD) for few months to induction insulin resistance and dyslipidemia ${ }^{30}$. Eventually, HFD led to hyperinsulinemia and hyperglycemia as symptoms of diabetic type-2 induction disease in rats. Postprandial glucose elevated in blood side by side with increased serum insulin level lead to impaired regulation of insulin action on glucose ${ }^{31}$.

Exactly, the $C$. dichotomy peel fiber as well as neutral detergent fiber (NDF) and hemicellulose was a big ratio of fiber content could be integration with pulp mucilage contains miscellaneous carbohydrate active ingredients as D-galactose, D-fructose, D-xylose, L-rhamnose and $D$-galacturonic acid. This integration may be regards to the poly saccharides linkage properties of $B$ bonds. Nevertheless, foods with high content of fiber already a low glycaemic index are a helpful alternative in controlling hyperglycemia ${ }^{32}$. Healthy importance among these foods are those with a high content of beta-glucans $\mathrm{s}^{33}$. These fibres appear to configure a barrier in the small intestine which prohibits glucose and other nutrients absorption, decreasing immediately the glycaemia or insulinaemia ${ }^{34}$. Also, these mucilage components had many functions on health for example 
D-xylose supplementation may have a beneficial effect on the postprandial glycemic response ${ }^{35}$. Many studies demonstrated on the insoluble fiber a resistance to absorption of fat in the small intestine and a carbs sugar. It's due to reduce the postprandial glucose in the blood. The supplementation with the pulp and peel powder of $C$. dechotoma may play role as same as mentioned previously. Another propose that insoluble fiber raises transit time of foodstuff through into the digestive system tract thus lead to reduce absorption of nutrients, namely simple carbohydrates. While, Weickert and Pfeiffer ${ }^{36}$ found that high intake of insoluble fiber significantly improved glucose level in blood disposal regard to in an $8 \%$ improvement of insulin sensitivity. Also, in the same way suggested that the mechanisms relation to insoluble fiber was more peripheral nutrient absorption. In normal healthy women study, the secretion of gastric inhibitory polypeptide was observed directly after the ingestion of an insoluble fiber ${ }^{37}$.

No doubt, it was noticed that fiber fraction had analogous water and oil absorption ability more than trade fiber products. Fiber fraction methodology using acid and alkaline sequent digestion to be isolated the indigestible fraction of insoluble fiber. The neutral detergent fibre method Van Soest and Robertson ${ }^{14}$ measuring the primary important analytical tool for determined the main portions content of dietary fiber. Food fibers have many functions and a health benefits unambiguously led to produce big and prospect market for fiber-rich products and functional fiber products. Recently, research concerned to find a highly useful of dietary fiber that a functional role used in the food industry ${ }^{38}$. Although, many studies have been paradoxical results, focusing no differentiation between soluble and insoluble fiber on diabetes $^{39}$, the research explain the risk of type- 2 diabetes correlate inverse relationship with insoluble fiber. A lot of epidemiological research of 42,000 men found that vegetables or fruits dietary fiber had any effects on the diabetic people. However, whole cereal grains dietary fiber appeared significant decrease in diabetes occurrence ${ }^{40}$.

Mainly, permanent oral intake to an HFD could affect at any or all of several levels of body and biochemical parameters in positive control rats (II) to induction obesity. For example: this might effect on taste or other sensory qualities of HFD, the digestion and absorption of lipid by the digestive system, the reception of meal-related signals that regulate food intake and biosynthesis, the controlling by the brain of adiposityindicating signals and/or neurotransmitter systems of brain that control and management food intake and metabolites. Permanent process that HFD-induced obesity was of substantial necessary and will require a well-established and controlled animal model on the long period nearly 3 months to incidence the diabetic rats as group III. In addition, diabetic rats combined with elevation in lipid profile as cholesterol, LDLC and tri-glyceride as observed in group II. According to Kelley and Mandarino ${ }^{41}$, increases in free fatty acids (FFA) level in the blood can prevent glucose metabolism through the suppression of GLUT 4 transporters. Also, evident from the plant used for various pharmaceutical purposes. Chromium exist in the $C$. dechotoma has therapeutic effect in diabetes. In addition, a fruit comprised some anti-nutritional agents such as phytate phosphorus (100 mg), phytic acid (355 mg) and oxalic acid ${ }^{42}(250 \mathrm{mg})$ per $100 \mathrm{~g}$. Tri-Glyceride was decreased significantly by administration $C$. dechotoma powder in hyperlipidemic rats, compared to HFD-control. Current approaches in decrease blood LDL-cholesterol by inhibiting cholesterol synthesis or blocking the absorption of dietary cholesterol ${ }^{43}$. Varieties of plants have been used traditionally in the treatment of various cardiovascular diseases as well as $C$. dichotoma powder.

It was obviously that the oxidative stress declined in group III which administrated C. dichotoma powder than group II. May lead to that diabetes mellitus is a disease combined with metabolic disorders as excess oxidative stress at all body organs and should incidence liver damage ${ }^{44}$. The free radicals of reactive oxygen species (ROS) of HFD utilized in induction diabetic rats are involved in the progression of diabetes risk factors. The ROS is free radical substances can oxidize lipids and other molecules to be stabilize themselves. Under normal conditions, ROS generated in the body can be removed by its natural antioxidant defenses ${ }^{45}$. Cordia dechotoma antioxidants had a potent role in protect the liver from oxidative damages of ROS and provide long-term mitigation of liver metabolic disorders ${ }^{46}$. Cordia dichotoma fruits pulp or seeds pulp contained useful compound and many biological activities. Fruits are important source of fibers, minerals, protein, vitamins and carbohydrates. Also, fruit contained high antioxidants (polyphenols content and flavonoids), tannins and saponins ${ }^{9}$. The synergism role of phytochemical compounds, boosted nutrient content and digestive properties are should be had the mechanism behind dietary fibers beneficial effects on the treatment and prevention of obesity and diabetes ${ }^{33}$.

\section{CONCLUSION}

Sweets and sweet fruits don't a device to diabetic people. C. dichotoma sweet fruit contain pulp is mucilage contains miscellaneous carbohydrate active ingredients; these mucilage components had many functions on health for 
example D-xylose supplementation may have a beneficial effect on the postprandial glycemic response. The biggest ratio of fiber fraction ( $\mathrm{ff}$ ) of $C$. dechotoma powder was $70.39 \%$ and the lowest ratio was cellulose (2.82\%).The risk of type-2 diabetes correlates inverse relationship with insoluble fiber and mucilage functional ingredients in C. dichotoma powder. The observation of results demonstrated that decreased of blood glucose in diabetic rats feeding diet mixed with $10 \%$ C. dichotoma powder also, relief of oxidative stress and reduce LDLC and cholesterol level in blood of induction diabetic rats.

\section{SIGNIFICANCE STATEMENT}

This finding of the research presented a novel fruit as well as antidiabetic effects can be a beneficial to protect from complication of diabetes syndrome. Furthermore, it will help researchers to an important topic on utilizing and exploring combinations of fruit with diabetic diet system or extracted in pharmaceutical formula will be potent anti-diabetes drugs.

\section{ACKNOWLEDGMENT}

The authors are grateful to animal house, National Research Centre for help and facilities which supported us to manage this research.

\section{REFERENCES}

1. WHO., 2011. Global Status Report on Non-Communicable Diseases 2010. World Health Organization, Geneva, ISBN: 9789241564229, Pages: 176.

2. Kumamoto, R., H. Uto, K. Oda, R. Ibusuki and S. Tanoue et al., 2013. Dietary fructose enhances the incidence of precancerous hepatocytes induced by administration of diethylnitrosamine in rat. Eur. J. Med. Res., Vol. 18. 10.1186/2047-783X-18-54.

3. Anonymous, 2012. Obesity, cardiovascular disease and diabetes regional statistics by country/state/province. http://www.juststand.org/Portals/3/literature/regionalStats. pdf.

4. Edijala, J.K., S.O. Asagba, G.E. Eriyamremu and U. Atomatofa, 2005. Comparative effects of garden egg fruit, oat and apple on serum lipid profile in rats fed a high cholesterol diet. Pak. J. Nutr., 4: 245-249.

5. Maghrani, M., A. Lemhadri, N.A. Zeggwagh, A. El-Amraoui, M. Haloui, H. Jouad and M. Eddouks, 2004. Effect of Retama raetam on lipid metabolism in normal and recent-onset diabetic rats. J. Ethnopharmacol., 90: 323-329.
6. Van Heek, M., C. Farley, D.S. Compton, L. Hoos, K.B. Alton, E.J.Sybertz and H.R. Davis Jr., 2000. Comparison of the activity and disposition of the novel cholesterol absorption inhibitor, SCH58235 and its glucuronide, SCH60663. Br. J. Pharmacol., 129: 1748-1754.

7. Wild, S., G. Roglic, A. Green, R. Sicree and H. King, 2004. Global prevalence of diabetes: Estimates for the year 2000 and projections for 2030. Diabetes Care, 27: 1047-1053.

8. Sharma, U.S., U.K. Sharma, N. Sutar, A. Singh and D.K. Shukla, 2010. Anti-inflammatory activity of Cordia dichotoma forst f. seeds extracts. Int. J. Pharm. Anal., 2: 1-4.

9. Rajashekar, K., M.K. Thupurani, S. Marupati and T.S. Prasad, 2014. Cordia dichotoma crude extracts: Potent source of natural antibacterial and antioxidant agents. Int. J., 2: 65-73.

10. Mishra, A. and G.P. Garg, 2011. Antidiabetic activity of fruit pulp of Cordia dichotoma in alloxan induced diabetic rats. Int. J. Pharm. Sci. Res., 2: 2314-2319.

11. Patel, A.K., N.L. Pathak, H.D. Trivedi, L.D. Patel, M.G. Gavania and H. Trivedi, 2011. Role of Cordia dichotoma on behavioral changes by using long-term hypoperfusion in rats. Int. J. Pharm. Res. Dev., 3: 6-17.

12. Reeves, P.G., F.H. Nielsen and G.C. Jr. Fahey, 1993. AIN-93 purified diets for laboratory rodents: Final report of the American institute of nutrition ad hoc writing committee on the reformulation of the AIN-76A rodent diet. J. Nutr., 123: 1939-1951.

13. AOAC., 2005. Official Methods of Analysis. 18th Edn., Association of Official Analytical Chemists, Washington, DC., USA.

14. Van Soest, P.J. and J.B. Robertson, 1979. What is fiber and fiber in food? Use of detergents in the analysis of fibrous feeds. Il. A rapid method for the determination of fiber and lignin. J. Nutr. Rev., 35: 12-22.

15. Allain, C.C., L.S. Poon, C.S.G. Chan, W. Richmond and P.C. Fu, 1974. Enzymatic determination of total serum cholesterol. Clin. Chem., 20: 470-475.

16. Fossati, P. and L. Prencipe, 1982. Serum triglyceride determination calorimetrically with an enzyme that produces hydrogen peroxide. Clin. Chem., 28: 2077-2080.

17. Levy, A.L., 1981. A fully enzymatic colorimetric determination of LDL cholesterol in the serum. Clin. Chem., 27: 653-662.

18. Burstein, M.A., 1970. Fully enzymatic colorimetric determination of HDL cholesterol in the serum. Lipid Res., 11: 583-595.

19. Reitman, S. and S. Frankel, 1957. Determination of glutamate pyruvat transaminase and glutamate oxaloacetate transaminase. Am. J. Clin. Pathol., 28: 56-63.

20. Draper, H.H. and M. Hadley, 1990. Malondialdehyde determination as index of lipid peroxidation. Meth. Enzymol., 186: 421-431. 
21. Bartholomew, R.J. and A.M. Delaney, 1966. Sulphonphthaleins as specific reagents for albumin: Determination of albumin in serum. Proc. Aust. Assoc. Clin. Biochem., 1: 214-218.

22. Fawcett, J.K. and J.E. Scott, 1960. A rapid and precise method for the determination of urea. J. Clin. Pathol., 13: 156-159.

23. Bartels, H., M. Bohmer and C. Heierli, 1972. [Serum creatinine determination without protein precipitation]. Clinica Chimica Acta, 37: 193-197, (In German).

24. Satoh, K., 1978. Serum lipid peroxide in cerebrovascular disorders determined by a new colorimetric method. Clin. Chim. Acta, 90: 37-43.

25. McCord, J.M. and I. Fridovich, 1969. Superoxide dismutase an enzymic function for erythrocuprein (Hemocuprein). J. Biol. Chem., 244: 6049-6055.

26. Weinhold, L.C., S. Ahmad and R.S. Pardini, 1990. Insect glutathione-S-transferase: A predictor of allelochemical and oxidative stress. Compar. Biochem. Physiol. B, Compara. Biochem., 95: 355-363.

27. Aebi, H., 1984. Catalase in vitro. Methods Enzymol., 105: 121-126.

28. Ellman, G.L., 1959. Tissue sulfhydryl groups. Arch. Biochem. Biophys., 82: 70-77.

29. COSTAT-C, 1988. COSTAT-C, a microcomputer program for the design, arrangement and analysis of agronomic research. Michigan State University, East Lansing, pp: 138.

30. Nascimento, A.R., M. Machado, N. de Jesus, F. Gomes, M.A. Lessa, I.T. Bonomo and E. Tibirica, 2013. Structural and functional microvascular alterations in a rat model of metabolic syndrome induced by a high fat diet. Obesity, 21: 2046-2054.

31. Aragno, M., C.E. Tomasinelli, I. Vercellinatto, M.G. Catalano and M. Collino etal., 2009. SREBP-1c in nonalcoholic fatty liver disease induced by Western-type high-fat diet plus fructose in rats. Free Radic. Biol. Med., 47: 1067-1074.

32. Kabir, M., J.M. Oppert, H. Vidal, F. Bruzzo and C. Fiquet et al., 2002. Four-week low-glycemic index breakfast with a modest amount of soluble fibers in type 2 diabetic men. Metab. Clin. Exp., 51: 819-826.

33. Jenkins, A., D. Jenkins, U.Zdravkovic, P. Wursch and V. Vuksan, 2002. Depression of the glycemic index by high levels of $\beta$-glucan fiber in two functional foods tested in type 2 diabetes. Eur. J. Clin. Nutr., 56: 622-628.

34. Seino, Y., K. Nanjo, N. Tajima, T. Kadowaki and A. Kashiwagi et al., 2010. Report of the committee on the classification and diagnostic criteria of diabetes mellitus. J. Diabetes Invest., 1: 212-228.
35. Jun, Y.J., J. Lee, S. Hwang, J.H. Kwak and H.Y. Ahn et al., 2016. Beneficial effect of xylose consumption on postprandial hyperglycemia in Korean: A randomized double-blind, crossover design. Trials, Vol. 17. 10.1186/s13063-016-1261-0.

36. Weickert, M.O. and A.F. Pfeiffer, 2008. Metabolic effects of dietary fiber consumption and prevention of diabetes. J. Nutr., 138: 439-442.

37. Weickert, M.O., M. Mohlig, C. Koebnick, J.J. Holst and P. Namsolleck et al., 2005. Impact of cereal fibre on glucose-regulating factors. Diabetologia, 48: 2343-2353.

38. Chau, C.F. and Y.L. Huang, 2003. Comparison of the chemical composition and physicochemical properties of different fibers prepared from the peel of Citrus sinensis L. Cv. Liucheng. J. Agric. Food Chem., 51: 2615-2618.

39. Schulze, M.B., S. Liu, E.B. Rimm, J.E. Manson, W.C. Willett and F.B. Hu, 2004. Glycemic index, glycemic load and dietary fiber intake and incidence of type 2 diabetes in younger and middle-aged women. Am. J. Clin. Nut., 80: 348-356.

40. Salmeron, J., A. Ascherio, E.B. Rimm, G.A. Colditz and D. Spiegelman et al., 1997. Dietary fiber, glycemic load and risk of NIDDM in men. Diabetes Care, 20: 545-550.

41. Kelley, D.E. and L.J. Mandarino, 2000. Fuel selection in human skeletal muscle in insulin resistance: A reexamination. Diabetes, 49: 677-683.

42. Deshmukh, A.S., C.M. Setty, A.M. Badiger and K.S. Muralikrishna, 2011. Cordia dichotoma gum: A functional polysaccharide for pharmaceutical applications. Int. J. Curr. Pharm. Res., 3: 10-13.

43. Van Heek, M., C. Farley, D.S. Compton, L.M. Hoos, A. Smith Torhan and H.R. Davis, 2003. Ezetimibe potently inhibits cholesterol absorption but does not affect acute hepatic or intestinal cholesterol synthesis in rats. Br. J. Pharmacol., 138: 1459-1464.

44. Giacco, F. and M. Brownlee, 2010. Oxidative stress and diabetic complications. Circ. Res., 107: 1058-1070.

45. Sottero, B., S. Gargiulo, I. Russo, C. Barale, G. Poli and F. Cavalot, 2015. Postprandial dysmetabolism and oxidative stress in type 2 diabetes: Pathogenetic mechanisms and therapeutic strategies. Med. Res. Rev., 35: 968-1031.

46. Xiao, J., K.F. So, E.C. Liong and G.L. Tipoe, 2013. Recent advances in the herbal treatment of non-alcoholic fatty liver disease. J. Tradit. Complement. Syst., 3: 88-94. 